\title{
Effectiveness of Structured Teaching Programme on Selected Common Behavioural Problems of Children
}

\author{
Sandeep Garg ${ }^{1}$, Arpan Pandya ${ }^{2}$ Ravindra H.N. ${ }^{3}$ \\ ${ }^{I}$ Student, Sumandeep Nursing College, Sumandeep Vidyapeeth, Piparia, Vadodara-391760, Gujarat, India, \\ ${ }^{2}$ Lecturer, Department Of Child Health Nursing, Sumandeep Nursing College, Sumandeep Vidyapeeth, Piparia, \\ Vadodara-391760, Gujarat, India, \\ ${ }^{3}$ Principal, Sumandeep Nursing College, Sumandeep Vidyapeeth, Piparia, Vadodara-391760, Gujarat, India.
}

\begin{abstract}
:
Background: Children are the most important asset and wealth of a nation. Healthy children make a healthy nation. The children under 15 years of age constitute about $40 \%$ of the population. The child is not a miniature, but an individual in his own right. The quality of childhood one has lived will determine the ultimate nature of the adulthood. Now a day, because of the rapid industrialization and urbanization, majority of young couples are employed, so unavoidably they get less time to look after their children. Under these circumstances, emotional, behavior and psychiatric problems are on the rise.
\end{abstract}

Aims and objectives: The study aimed at assessing the knowledge of Primary school teachers regarding Selected Common Behavioural Problems of Children, evaluate the effectiveness of Structure Teaching Programme on Selected Common Behavioural Problems of Children and find out association between pre test knowledge score and selected demographic variables.

Material and Methods: A one group pre-test post-test pre-experimental design and evaluative approach was adopted. The study was conducted among 60 primary school teachers conveniently selected from five primary schools of Vadodara.

Results: The results of the study shows that in pre test, primary school teachers were having on average $49.40 \%$ knowledge regarding selected common behavioural problems of children and mean score was $14.82 \pm 3.372$ and in post test, average $75.83 \%$ knowledge regarding regarding selected common behavioural problems of children and mean score was $22.75 \pm 2.802$. T calculated value is 33.233 which is more than the tabulated value of 2.00 at 0.05 level of significance.

Conclusion: This study concluded that structure teaching program is effective tools to improve the knowledge of primary school teachers regarding Selected Common Behavioural Problems of Children.

Key words: Assess, Effectiveness, Knowledge, Structured teaching programme, selected common behavioral problems of children, Primary school teachers

\section{Introduction}

Family and society are the two main institutions which mould one child's development and behaviour and in that, schools play a primordial position. ${ }^{2}$ School children's emotional and behavioural problems have a substantial adverse impact on families, schools and children. These disorders must be identified and treated early in order to allow children to learn effectively. ${ }^{[1]}$

The term behaviour refers to the way a person responds to a certain situation or experience. Behaviour is affected by temperament, which is made up of an individual's innate and unique expectations, emotions and beliefs. Behaviour can also be influenced by a range of social and environmental factors including parenting practices, gender, and exposure to new situations, general life events and relationships with friends and siblings. ${ }^{[2]}$

The etiological factors for behavioural problems of children are usually biological risk factors, genetic risk factors, family relationship risks, experiential risks and social environmental risk factors. A number of specific biological factors arc associated with behavioral and developmental problems, mainly they contribute to behavioral \& emotional difficulties. Prenatal exposure to alcohol, tobacco smoke \& drugs also has been found to have an impact on ueurecognitive process $\&$ is associated with a variety of behavioral problems. ${ }^{[3]}$

There are various behavioural disorders evident in children. Major concerns of them are autism, attention deficit hyperactivity disorder, and school phobia which are mainly found in school age children

The Centers for Disease Control and Prevention estimates that 1 in 88 children in the United States has been identified as having an autism spectrum disorder, according to a new study released today that looked at data from 14 communities. Autism spectrum disorders are almost five times more common among boys than girls - with 1 in 54 boys identified. ${ }^{[4]}$ 
Daijiworld Mangalore (Jan 30, 2012) reported that one among the many common behavioral disorders seen among children in the recent times is Attention Deficiency/Hyperactivity Disorder. Though the disorder affects millions of children all over the world many believe that that the disorder has not got the attention it deserves in India and it continues to haunt children and parents alike. According to the latest survey conducted by Associated Chambers of Commerce and Industry in India, the details of which were released recently, prevalence of children diagnosed with Attention Deficiency/Hyperactivity Disorder in India has gone up from $4 \%$ to $11 \%$ in the last six years. ${ }^{[5]}$

Prabhuswami M et al (2007) conducted a study on outcome of children with school refusal. In that 33 subjects (8-16 year old) presenting with school refusal were evaluated. Results showed 87.9\% had a psychiatric diagnosis at baseline. Depression was seen among $63.6 \%$ and phobias in $30.3 \%$. The study concluded that psychiatric morbidity is high in youngsters with school refusal. ${ }^{[6]}$

As review literature shows that the evidence of behavioural problems is increasing day by day in children. Primary school teachers are having some knowledge regarding behavioural problems. Primary school teachers need more knowledge regarding behavioural problems. Teachers plays very important role in early diagnosis and promotion of behavioural problems among children in their schools. By keeping all these points in brain, researcher has selected the topic on common behavioural problems of children among primary school teachers in selected schools at Vadodara.

\section{Statement Of The Problem}

"A study to assess the effectiveness of Structured Teaching Programme on knowledge regarding selected common behavioural problems of children among primary school teachers in selected schools at Vadodara."

\section{Objectives Of The Study}

1. To assess the existing knowledge of primary school teachers regarding selected common behavioural problems of children.

2. To evaluate an effectiveness of Structure teaching programme regarding selected common behavioural problems of children.

3. To find out the association between the post-test knowledge scores and selected demographic variables such as age, gender, educational qualification, years of teaching experience, religion and undergone any training related to management of child with behavioural problems.

\section{Hypothesis:}

H1: There will be significant difference between pre-test and post-test knowledge scores of primary school teachers regarding selected common behavioural problems of children.

$\mathrm{H}$ 2: There will be a significant association between post-test knowledge scores and selected demographic variables

\section{Materials And Methods}

Research Approach: Evaluative research approach was used.

Research Design: A one group pre-test post-test Pre experimental research design was adopted

Setting of the Study: The study was conducted in five selected primary schools of Vadodara.

Target Population: The target population for this study consisted of primary school teachers.

Sample: The sample for the present study comprises of 60 primary school teachers of selected primary schools of Vadodara.

Sampling technique: Non-probability convenience sampling technique was used to select the sample for this study.

Development of tool for data collection: it consists of 2 parts:- The researcher prepared a Self Reportive Structured Interview questionnaire is used as tool for the study. The Self Reportive Structured Interview tool consists of two parts

Part A: It is designed to obtain general information of the respondents and it consists of six items related to the demographic variables of the primary school teachers.

Part B: It consists of thirty items regarding knowledge of primary school teachers regarding the knowledge on selected common behavioural problems of children.

Validity of instrument: The Self Reportive Structured Interview tool and Structured Teaching Programme were given to 12 experts along with the blue print and objectives of the study to establish the content validity of the tool and STP regarding selected common behavioural problems of children. The experts were from the field 
of Nursing and Medical, Research department. They were requested to give their opinion and suggestions regarding the relevancy of the items in the tool.

Reliability: After obtaining formal administrative permission the Gujarat and English version of the tool was administered to 6 samples selected as per the set criteria. The scores were calculated and then given for statistical analysis. The reliability was established by using split half method.

Data collection procedure: A formal permission was obtained from the five selected schools of Vadodara district. Data was collected from November $18^{\text {th }}$ to December $02^{\text {nd }}$ 2013. After identifying the samples objectives of the study were discussed and consent for the participation in the study was taken from the selected group. The investigator assured the subjects about the confidentiality of the data. The investigator herself administered the questionnaire for the pre-test.

Analysis of data: Both descriptive and inferential statistics analyzed on the basis of the objectives and hypotheses of the study. The knowledge of primary school teachers regarding selected common behavioural problems of children assessed before and after the administration of STP would be calculated using frequency, mean, and standard deviation and inferential statistics used to analyze Paired ' $t$ ' test and ANOVA test. The data was also presented graphically and in the form of table.

\section{Results}

The analysis is made on the basis of objectives and hypothesis. The data analysis is planned to include descriptive and inferential statistics. Data is analysis in following parts:

Section I: Description of the demographic variables of primary school teachers

Section II: Analysis of existing knowledge of primary school teachers regarding selected common behavioural problems of children.

Section III: Analysis of effectiveness of structured teaching program regarding selected common behavioural problems of children.

Section IV: Association of demographic variable with the level of post-test knowledge score of primary school teachers

\section{Section I: - Description Of The Demographic Variables Of Primary School Teachers:-}

$>$ Distribution of respondents in relation to age in year the majority $35(58.3 \%)$ respondents belongs to the age group of below - 30 years of age while in the age group of $30-39$ years $18(30 \%)$ respondents belongs to this category and $6(10 \%)$ respondents belongs to $40-49$ years. In the age group of more than 50 and above years $1(1.7 \%)$ respondents have been observed in this particular study.

$>$ Distribution of respondents in relation to gender of the primary school teachers depicts the finding shows that respondents are $6(10 \%)$ male and $54(90 \%)$ female.

$>$ Distribution of respondents in relation to educational qualification revealed that Majority of 24 (40\%) teachers are with Graduation with B.Ed. while $16(26.7 \%)$ teachers are Graduate, $11(18.3 \%)$ teachers are Post Graduate with M.Ed. and $9(15 \%)$ of the teachers belong to D.Ed. or P.T.C.

$>$ Distribution of respondents in relation to teaching experience revealed that Majority of $29(48.3 \%)$ teachers have below 3 years of experience while 18 (30\%) teachers are having 3-6 years, $7(11.7 \%)$ teachers belong to 10 years and above of experience and $6(10 \%)$ teachers have $7-9$ years of teaching experience.

$>$ Distribution of respondents in relation to religion revealed that majority 58 (96.7\%) of the respondents are Hindu, $1(1.7 \%)$ of the respondents are Muslim where as other respondents are $1(1.7 \%)$ which was Sikh and no respondents belong to Christian religion.

$>$ Distribution of respondents in relation to undergone any training related to management of child with behavioural problems majority revealed that no one respondent have not undergone any training related to management of child with behavioural problems.

\section{Section II: - Analysis of Existing Knowledge Of Primary School Teachers:-}

The data shows that, in pre test, primary school teachers were having on average $49.40 \%$ knowledge regarding selected common behavioural problems of children and mean score was $14.82 \pm 3.372$.

Table No.1: Pre-test knowledge score regarding selected common behavioural problems of children

\begin{tabular}{|c|c|c|c|c|c|c|}
\hline \multicolumn{7}{|c|}{ Percentage and Mean of the pre-test } \\
\hline & $\mathrm{N}$ & Minimum & Maximum & $\begin{array}{c}\text { Percentage } \\
\mathbf{\%}\end{array}$ & Mean & Std. Deviation \\
\hline Total & 60 & \multirow{2}{*}{8} & \multirow{2}{*}{22} & \multirow{2}{*}{49.40} & \multirow{2}{*}{14.82} & \multirow{2}{*}{3.372} \\
\hline Valid N & 60 & & & & & \\
\hline
\end{tabular}


Section III: Analysis Of Effectiveness Of Structured Teaching Program Regarding Selected Common Behavioural Problems Of Children.

Since p-value $=0.000<0.01$, the difference between the Pre-test and Post-test scores is highly significant at $1 \%$ level of significance this shows that the Structured Teaching Programme on selected common behavioural problems of children is effective.

\begin{tabular}{|c|c|c|c|c|c|c|}
\hline \multicolumn{7}{|c|}{ Paired sample statistics: Effectiveness of STP } \\
\hline & Mean & $\begin{array}{c}\text { Percentage } \\
\%\end{array}$ & Std. Deviation & $\mathbf{T}$ & $\mathbf{P}$ & Significant level \\
\hline $\begin{array}{c}\text { Pre test } \\
\text { score }\end{array}$ & 14.82 & 49.40 & 3.372 & \multirow{2}{*}{33.233} & \multirow{2}{*}{.000} & \multirow{2}{*}{ Significant } \\
\hline $\begin{array}{c}\begin{array}{c}\text { Post test } \\
\text { score }\end{array}\end{array}$ & 22.75 & 75.83 & 2.802 & & & \\
\hline
\end{tabular}

Table No. 3: Comparison of the pre-test and post-test knowledge score of primary school teachers.

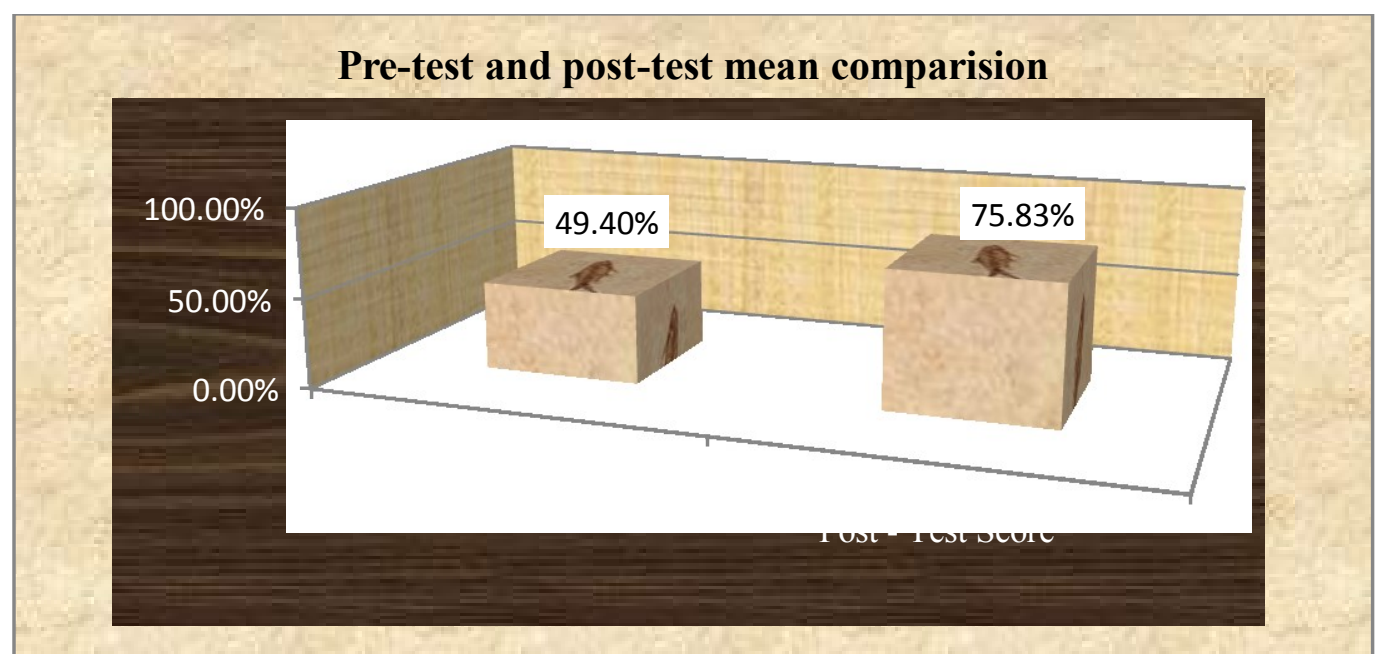

Figure No.1: Mean difference of Pre-test and Post-test mean score

Section IV: Association Of Demographic Variable With The Level Of Post-Test Knowledge Score Of Primary School Teachers

\begin{tabular}{|c|c|c|c|c|c|c|c|}
\hline \multicolumn{2}{|c|}{ Demographic Variables } & Mean & $\mathbf{N}$ & S.D. & $\mathbf{F}$ & P Value & Significance \\
\hline \multirow{4}{*}{ 1.Age in years } & Below - 30 & 22.71 & 35 & 3.064 & \multirow{4}{*}{1.148} & \multirow{4}{*}{.338} & \multirow{4}{*}{ Not Significant } \\
\hline & $30-39$ & 22.56 & 18 & 2.549 & & & \\
\hline & $40-49$ & 24.17 & 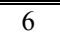 & 1.169 & & & \\
\hline & 50 - above & 19.00 & 1 & - & & & \\
\hline \multirow{2}{*}{ 2.Gender } & Male & 23.17 & 6 & 2.927 & \multirow{2}{*}{.145} & \multirow{2}{*}{.704} & \multirow{2}{*}{ Not Significant } \\
\hline & Female & 22.70 & 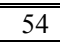 & 2.813 & & & \\
\hline \multirow{4}{*}{$\begin{array}{l}\text { 3.Educational } \\
\text { qualification }\end{array}$} & $\begin{array}{ll}\text { D.Ed. } & \text { or } \\
\text { P.T.C. } & \\
\end{array}$ & 22.33 & 9 & 3.464 & \multirow{4}{*}{.764} & \multirow{4}{*}{.519} & \multirow{4}{*}{ Not Significant } \\
\hline & $\begin{array}{l}\text { Graduation } \\
\end{array}$ & 22.81 & 16 & 2.562 & & & \\
\hline & $\begin{array}{l}\text { Graduation } \\
\text { with B.Ed. }\end{array}$ & 23.29 & 24 & 2.236 & & & \\
\hline & $\begin{array}{l}\text { Post } \\
\text { graduation } \\
\text { with M.Ed. } \\
\end{array}$ & 21.82 & 11 & 3.683 & & & \\
\hline \multirow{4}{*}{$\begin{array}{l}\text { 4.Years of } \\
\text { teaching } \\
\text { Experience }\end{array}$} & Below 3 years & 22.83 & 29 & 3.241 & \multirow{4}{*}{.628} & \multirow{4}{*}{.600} & \multirow{4}{*}{ Not Significant } \\
\hline & 3-6 years & 22.11 & 18 & 2.471 & & & \\
\hline & $7-9$ years & 23.17 & 6 & 2.483 & & & \\
\hline & $\begin{array}{l}10 \text { years and } \\
\text { above }\end{array}$ & 23.71 & 7 & 1.799 & & & \\
\hline \multirow{4}{*}{ 5.Religion } & Hindu & 22.76 & 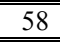 & 2.849 & \multirow{4}{*}{.039} & \multirow{4}{*}{.962} & \multirow{4}{*}{ Not Significant } \\
\hline & Muslim & 23.00 & 1 & $\begin{array}{ll}- \\
\end{array}$ & & & \\
\hline & Christian & $\begin{array}{ll}- \\
\end{array}$ & - & 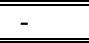 & & & \\
\hline & $\begin{array}{l}\text { Others } \\
\end{array}$ & 22.00 & 1 & 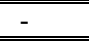 & & & \\
\hline \multirow{2}{*}{$\begin{array}{l}6 . \text { Under gone } \\
\text { any training }\end{array}$} & No & 22.75 & 60 & 2.802 & \multirow{2}{*}{\multicolumn{3}{|c|}{ No variance within groups }} \\
\hline & Yes & - & - & 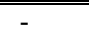 & & & \\
\hline
\end{tabular}

Table No.4: Association between post-test knowledge score and demographic variables 
The data presented in table shows association of the post test knowledge score with demographic variables at 0.05 significant levels.

Age: The impact of age in years on mean knowledge score on selected common behavioural problems of children found to be no significant which is established by $\mathrm{P}$ value. Because the $\mathrm{P}$ value is more than 0.05 .

Educational qualification: The impact of educational qualification on mean knowledge score on selected common behavioural problems of children found to be no significant which is established by P value. Because the $\mathrm{P}$ value is more than 0.05 .

Years of teaching experience: The impact of years of teaching experience on mean knowledge score on selected common behavioural problems of children found to be no significant which is established by $\mathrm{P}$ value. Because the $\mathrm{P}$ value is more than 0.05 .

Religion: The impact of religion on mean knowledge score selected common behavioural problems of children found to be no significant which is established by $\mathrm{P}$ value. Because the value is more than 0.05 .

Undergone any training related to management of child with behavioural problems of children: The impact of undergone any training related to management of child with behavioural problems of children on mean knowledge score on selected common behavioural problems of children found to be no variance within groups.

\section{Conclusion}

The findings of this study have been discussed with reference to the objectives and hypothesis. The pre testing of primary school teacher's knowledge regarding selected common behavioural problems of children show that primary school teachers have less knowledge about selected common behavioural problems of children. This indicates the need for imparting necessary education and information regarding selected common behavioural problems of children.

\section{Acknowledgement}

I express my gratitude and thanks towards all who have directly or indirectly helped me to complete this study and their support in each major step of the study.

\section{Limitations Of The Study}

The following points were beyond the control of the investigator.

$>\quad$ A limited time available for data collection.

> Sample was selected only from few areas of Vadodara District.

$>\quad$ The study was confined to 60 subjects, which resulted in reduced power in statistical analysis.

$>$ The study is limited to primary school teachers who are willing to participate in the study.

\section{Recommendations}

Based on the findings of the present study recommendations offered for the future study are:

$>\quad$ Similar study can be conducted on a larger sample.

$>$ A comparative study can be conducted with control group.

Similar study can be conducted with different population and setting.

$>\quad$ Study can be done to assess the effectiveness of structure teaching programme regarding selected common behavioural problems of children.

\section{Ethical Standards}

This study was conducted after getting approval from the Institutional Ethics Committee and after obtaining written consents from all subjects.

Source of funding: The authors did not receive any financial support from any third party related to the submitted work.

Conflict of interest: The authors had no relationship/condition/circumstances that present a potential conflict of interest.

\section{References}

[1]. Ladwig R J, Khan K A. School Avoidance: Implications for School Nurses. Journal of social and preventive nursing 2007; 12(3): 210-12

[2]. Centre for Community Child Health 2006, Behavior Problems pp 8, Downloaded from www.raisingchildren.net.au

[3]. ICD - 10, World Health Organisation, Geneva 1992, $247-263$ PP

[4]. http://www.cdc.gov/media/releases/2012/p0329_autism_disorder.html

[5]. http://www.daijiworld.com/news/news_disp.asp? $\mathbf{n}$ id $=\overline{128571}$

[6]. Prabhuswami M, Srinath S, et al,Outcome of children with school refusal, Indian Journal of Pediatrics, 2007, April, pg no: $375-309$. 